\title{
Efeito da adição de fibra de aveia sobre as propriedades físico-químicas de hambúrguer cozido e congelado com redução de gordura e sal
}

\author{
Effect of the addition of oat fiber on the physicochemical properties of cooked \\ frozen hamburger with reduced fat and salt
}

\author{
Yara Cavalcanti Trevisan', Camila Vespúcio Bis¹, Jenifer Monari Henck', Andrea Carla da Silva Barretto ${ }^{\text {* }}$ \\ ${ }^{1}$ Universidade Estadual Paulista (UNESP), Instituto de Biociências, Letras e Ciências Exatas (IBILCE), São José do Rio Preto/SP - Brasil
}

\section{*Corresponding Author}

Andrea Carla da Silva Barretto, Universidade Estadual Paulista (UNESP), Instituto de Biociências, Letras e Ciências Exatas (IBILCE), Departamento de Engenharia e Tecnologia de Alimentos, Rua Cristóvão Colombo, 2265, CEP: 15054-000, São José do Rio Preto/SP - Brasil, e-mail: andreasb@ibilce.unesp.br

Cite as: Effect of the addition of oat fiber on the physicochemical properties of cooked frozen hamburger with reduced fat and salt. Braz. J. Food Technol., v. 19, e2015079, 2016.

Received: Oct. 05, 2015; Accepted: Sept. 14, 2016

\section{Resumo}

Novos produtos cárneos de fácil preparo e com apelo de mais saudáveis têm sido desenvolvidos para satisfazer consumidores que buscam por praticidade aliada à redução nos teores de gordura e sal. Novos ingredientes são testados para causar menos impacto na textura, no rendimento e em outras propriedades físico-químicas destes produtos. O presente estudo teve como objetivo avaliar a adição de fibra de aveia sobre as propriedades físico-químicas de hambúrgueres cozidos e congelados de carne bovina e carne mecanicamente separada de frango, com redução de gordura e sal. Foram determinados a composição centesimal dos hambúrgueres, perfil de textura, rendimento, encolhimento, rendimento após o aquecimento por micro-ondas, além da determinação da cor objetiva durante estocagem sob congelamento. A adição de $6 \%$ de fibra de aveia em hambúrguer de carne bovina e carne mecanicamente separada de frango com redução da adição de gordura e de sal aumentou o rendimento, diminuiu a perda de peso durante o aquecimento por micro-ondas e melhorou a estabilidade da cor durante a estocagem sob congelamento por 60 dias. Tanto os hambúrgueres com adição de $3 \%$ como de $6 \%$ de fibra de aveia tiveram valores para dureza, mastigabilidade e coesividade similares ao controle, com adição de gordura e sem redução de sal. Houve redução de 35\% no teor de gordura para os tratamentos com adição de fibra de aveia, em relação ao controle, com adição de gordura e sem redução de sal. A fibra de aveia pode ser considerada um ingrediente promissor para auxiliar formulações de produtos cárneos com redução de sal e gordura.

Palavras-chave: Rendimento; Encolhimento; Perda de peso por micro-ondas; Dureza.

\section{Summary}

New, healthier and easy to prepare meat products have been developed in order to satisfy consumers looking for convenience together with reduced fat and salt contents. New ingredients are tested to cause less impact on the texture, yield and other physicochemical properties of these products. This study aimed to evaluate the addition of oat fiber on the physicochemical properties of cooked and frozen hamburgers made from beef and mechanically deboned chicken meat with reduced fat and salt contents. The analyses carried out were the proximate composition, texture profile, yield, shrinkage and yield after heating in a microwave oven, besides the determination of instrumental colour during storage. The addition of $6 \%$ oat fibre to the hamburgers made from beef and mechanically deboned chicken meat with reduced fat and salt contents, increased the yield, decreased the weight loss during microwave heating and improved the colour stability during 60 days of frozen storage. Both the hamburgers with $3 \%$ and $6 \%$ of added oat fibre showed values for hardness, cohesiveness and chewiness similar to those of the control with added fat and no salt reduction. There was a reduction of $35 \%$ in the fat content for the treatments with added oat fibre as compared to the control with added fat and no salt reduction. Oat fibre can be considered a promising ingredient to assist the formulation of meat products with reduced salt and fat contents.

Keywords: Yield; Shrinkage; Weight loss during microwave heating; Hardness. 
Efeito da adição de fibra de aveia sobre as propriedades físico-químicas de hambúrguer cozido e congelado com redução de gordura e sal

Trevisan, Y. C. et al.

\section{Introdução}

A busca por produtos alimentícios mais convenientes tem trazido novidades principalmente para aqueles produtos de fácil preparo ou prontos para consumo. Em produtos cárneos, é possível verificar essas inovações principalmente em produtos congelados. Além da conveniência, o mercado tem exigido novos produtos relacionados a uma dieta mais saudável, com foco na redução de sódio e gordura dos produtos cárneos.

O consumo de carne e produtos cárneos com elevado teor de gordura saturada e sódio está sendo associado ao aumento do risco de doenças crônicas não transmissíveis como hipertensão, obesidade e doenças cardiovasculares (FERNÁNDEZ-GINÉS et al., 2005; WEISS et al., 2010; TALUKDER, 2015).

Hambúrgueres são produtos cárneos de fácil preparo e consumidos por todas as classes populares (OLIVEIRA et al., 2013). De acordo com a legislação brasileira (BRASIL, 2000) podem ser comercializados crus congelados ou cozidos congelados. Nas gôndolas dos supermercados, observa-se que o hambúrguer na forma crua e congelada é a principal escolha dos consumidores brasileiros. Porém, hambúrgueres cozidos congelados podem ser comercializados na forma de lanches congelados, que são preparados para consumo com o aquecimento em forno micro-ondas, oferecendo ao consumidor uma opção de rápido preparo.

A redução de sódio e de gordura pode trazer alterações nas propriedades tecnológicas, como no perfil de textura e presença de líquido exsudado, além das alterações nas propriedades sensoriais (WEISS et al., 2010). Ingredientes têm sido utilizados para a substituição da gordura animal nos produtos cárneos por misturas de amido ou gomas (ÁLVAREZ; BARBUT, 2013; BORTNOWSKA et al., 2014; CHOI et al., 2013), por óleos vegetais (COFRADES et al., 2013; COFRADES et al., 2014; SALCEDO-SANDOVAL et al., 2013) e por diferentes fibras alimentares (MANSOUR; KHALIL, 1999; ULU, 2004; CHOE et al., 2013; PIÑERO et al., 2008; TOMASCHUNAS et al., 2013; KTARI et al., 2014; BARRETTO et al., 2015; SCHMIELE et al., 2015).

O cloreto de sódio, em produtos cárneos, desempenha um papel importante na textura, melhora as propriedades de capacidade de retenção de água e gordura, afeta o sabor e atua como conservante por reduzir a atividade de água (RUUSUNEN; PUOLANNE, 2005). A fibra de aveia como substituto de gordura em produtos cárneos tem mostrado resultados positivos em relação ao rendimento e também à textura (KEETON, 1994; YILMAZ; DAGHOGLU, 2003). Substitutos parciais de cloreto de sódio, como cloreto de potássio, cloreto de magnésio e cloreto de cálcio têm sido utilizados em diferentes produtos cárneos com bons resultados tecnológicos, quando utilizados como misturas (SANTOS et al., 2014; HORITA et al., 2011). objetivo deste estudo foi avaliar a influência da adição de $3 \%$ e $6 \%$ de fibra de aveia sobre as propriedades físico-químicas de hambúrgueres cozidos e congelados, contendo carne bovina e carne mecanicamente separada de frango, com 35\% de redução de gordura e 50\% de redução de sal.

\section{Material e métodos}

Foram utilizadas carne de dianteiro bovino (acém), carne mecanicamente separada de frango (CMS) e gordura suína (toucinho), obtidas de frigoríficos da região de São José do Rio Preto (SP). Todos os materiais foram trazidos para o Laboratório de Carnes e Produtos Derivados do Instituto de Biociências, Letras e Ciências Exatas da Universidade Estadual Paulista "Júlio de Mesquita Filho" e foram mantidos congelados a $-18{ }^{\circ} \mathrm{C}$ até serem utilizados. A carne de dianteiro bovino e a gordura suína foram separadamente moídas (Bermar, São José do Rio Preto, SP) em disco de $5 \mathrm{~mm}$.

Todos os hambúrgueres tiveram a adição de 45\% de acém bovino, 27\% de carne mecanicamente separada de frango, 0,25\% de tripolifosfato de sódio (Kraki, Santo André, SP), 0,2\% de condimento para hambúrguer B-670 (Bremil, Arroio do Meio, RS), contendo 84-90\% de cloreto de sódio, 10\% de proteína de soja, aroma idêntico ao natural de mostarda e de pimenta do reino, 0,5\% de eritorbato de sódio (Kraki, Santo André, SP), 2\% de proteína texturizada de soja (Bremil, Arroio do Meio, RS) e 0,15\% de glutamato de sódio (Ajinomoto, Limeira, SP). À formulação básica foi adicionada Salona, que é um substituto de sal fornecido pela empresa ICL Food Specialties (São Paulo, SP), composto principalmente por $33 \%$ de cloreto de magnésio, 23\% de cloreto de potássio e teor máximo de $7 \%$ de cloreto de sódio. A fibra de aveia adicionada aos produtos foi fornecida pela empresa J. Rettenmaier Lationoamericana Ltda. (São Paulo, SP), com $93 \%$ de fibras insolúveis e teor máximo de $3 \%$ de fibras solúveis, pH entre 5,5 e 7,5, de acordo com a especificação técnica da empresa. Quatro diferentes tratamentos contendo $1,6 \mathrm{~kg}$ cada foram produzidos e as diferenças entre as formulações estão apresentadas na Tabela 1. O processamento ocorreu em triplicata, em dias diferentes.

Tabela 1. Composição dos hambúrgueres. Ingredientes $\begin{array}{llll}\text { C1(\%) } & \text { C2(\%) } & \text { T1(\%) } & \text { T2(\%) }\end{array}$

$\begin{array}{lllll}\text { Gordura suína } & 13,7 & 3,7 & 3,7 & 3,7\end{array}$

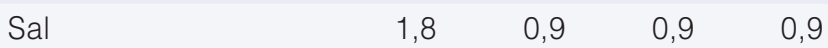

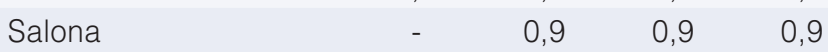

$\begin{array}{llll}\text { Água } & 9,4 & 19,4 & 16,4\end{array}$

Fibra de aveia 3

6

C1: sem redução de gordura e sal e sem adição de fibra de aveia; C2: com redução de gordura e sal e sem adição de fibra de aveia; T1: com redução de gordura e sal e com adição de 3\% de fibra de aveia; T2: com redução de gordura e sal e com adição de $6 \%$ de fibra de aveia. 
Efeito da adição de fibra de aveia sobre as propriedades físico-químicas de hambúrguer cozido e congelado com redução de gordura e sal

Trevisan, Y. C. et al.

Todos os ingredientes foram pesados e misturados manualmente por 5 minutos conforme cada formulação e depois foram moldados com o auxílio de um molde para hambúrguer (porção de $100 \mathrm{~g}$ ). Posteriormente foram cozidos em forno a gás (modelo Turbo 240 Classic, marca Passiani, Itajobi, SP), até que a temperatura interna atingisse $75^{\circ} \mathrm{C}$. Os hambúrgueres foram resfriados, embalados individualmente em sacos de polietileno e congelados em freezer horizontal (marca Reubly, Timoteo, MG). Os hambúrgueres foram estocados em câmara a $-18^{\circ} \mathrm{C}$ durante 60 dias para avaliação.

Métodos da AOAC (HORWITZ, 2007) foram seguidos nas determinações de umidade (950.46), cinzas (920.153) e proteínas (928.08). Os lipídeos foram determinados pelo método de Bligh e Dyer (1959). O pH foi medido através do pHmetro digital PG 1800, da marca GEHAKA (São Paulo, SP), com sonda de penetração durante 0, 30 e 60 dias de estocagem sob congelamento. Todas as determinações foram feitas em triplicata.

O rendimento foi calculado em triplicata, de acordo com a Equação 1, e a porcentagem de encolhimento dos hambúrgueres em triplicata, com base na variação do diâmetro do produto cru e cozido, de acordo com a Equação 2.

$$
\begin{aligned}
& \text { \%Rendimento }=\frac{\text { Peso dohambúrguer cozido }}{\text { Peso dohambúrguercru }} \times 100 \\
& \% \text { Encolhimento }=\frac{(\text { Diâmetro dohambúrguer cru }- \text { Diâmetro dohamb.cozido })}{\text { Diâmetro dohambúrguer cozido }} \times 100
\end{aligned}
$$

Foi avaliada a perda de peso no forno micro-ondas (PPMO) dos hambúrgueres, em triplicata, durante o aquecimento por dois minutos (tempo necessário para que as amostras congeladas atingissem temperatura de $75^{\circ} \mathrm{C}$ no seu centro geométrico).

A cor experimental foi determinada com espectrofotômetro Colorflex Hunter-Lab (modelo MiniScan XE Plus, VA, USA), operando com iluminante D65, ângulo do observador $10^{\circ}$, no sistema de cor CIELab. A determinação da cor foi realizada no período de 0,30 e 60 dias de estocagem dos hambúrgueres, com seis medições em cada formulação $(n=3)$.

A análise do perfil de textura foi realizada na amostra cozida e descongelada à temperatura de refrigeração, de um dia para o outro, e posteriormente colocada na temperatura ambiente até que a temperatura da amostra atingisse $25^{\circ} \mathrm{C}$. Foi utilizado o Texturômetro TA-XT2 Plus (Stable Micro Systems, Godalming, UK), após o período de 15 dias de estocagem, com oito replicatas $(n=3)$. As amostras foram comprimidas a $50 \%$ de sua altura original, com velocidade de $1 \mathrm{~mm} / \mathrm{s}$. Foram avaliados os parâmetros de: dureza: força máxima requerida para compressão da amostra (N); coesividade: resistência das ligações internas constituintes do produto (adimensional); elasticidade: taxa na qual um material deformado volta à sua forma original após uma força de deformação (adimensional); mastigabilidade: energia necessária para tornar-se um alimento sólido pronto para deglutição (N/cm) (CIVILLE; SZCZESNIAK, 1973). As amostras foram moldadas com o auxílio de um cortador de aço inox de $20 \mathrm{~mm}$ de diâmetro. O probe utilizado na análise foi cilíndrico de $25 \mathrm{~mm}$ de diâmetro.

Os dados foram avaliados por meio de análise de variância (ANOVA) e a diferença entre as médias dos resultados foi avaliada pelo Teste de Tukey, em um nível de confiança de 95\%, com o software MiniTab 16.

\section{Resultados e discussão}

Os resultados das determinações de umidade, cinzas, gordura, proteína, rendimento, encolhimento e perda de peso no micro-ondas estão expressos na Tabela 2.

Com relação à umidade, a formulação $C 1$ foi diferente das demais, devido à menor adição de água e à quantidade de gordura e sal adicionada. A umidade de $\mathrm{C} 2$ foi maior que a de $\mathrm{C} 1$, pois houve maior adição de água em função da redução de gordura e sal. Selani et al. (2016) também atribuíram as diferenças apresentadas no

Tabela 2. Teor de umidade, cinzas, gordura, proteína, rendimento, encolhimento e PPMO dos hambúrgueres cozidos congelados $(n=3)$.

\begin{tabular}{lrrrr}
\multicolumn{1}{c}{ Propriedades } & \multicolumn{3}{c}{ Formulações } \\
\cline { 2 - 5 } \multicolumn{1}{c}{ físico-químicas } & \multicolumn{1}{c}{ C1 } & \multicolumn{1}{c}{ C2 } & \multicolumn{1}{c}{ T1 } & T2 \\
\hline Umidade (\%) & $54,63 \pm 0,28^{\mathrm{c}}$ & $62,05 \pm 0,13^{\mathrm{a}}$ & $60,75 \pm 0,59^{\mathrm{ab}}$ & $59,87 \pm 0,06^{\mathrm{b}}$ \\
Cinzas (\%) & $3,24 \pm 0,01^{\mathrm{a}}$ & $2,99 \pm 0,00^{\mathrm{b}}$ & $2,97 \pm 0,01^{\mathrm{b}}$ & $2,82 \pm 0,07^{\mathrm{c}}$ \\
Gordura (\%) & $19,01 \pm 0,92^{\mathrm{a}}$ & $15,41 \pm 0,88^{\mathrm{b}}$ & $12,29 \pm 0,37^{\mathrm{c}}$ & $11,94 \pm 0,36^{\mathrm{c}}$ \\
Proteína (\%) & $18,92 \pm 0,86^{\mathrm{a}}$ & $19,25 \pm 0,43^{\mathrm{a}}$ & $18,23 \pm 0,45^{\mathrm{ab}}$ & $16,99 \pm 0,51^{\mathrm{b}}$ \\
Rendimento (\%) & $77,39 \pm 1,51^{\mathrm{b}}$ & $70,66 \pm 1,37^{\mathrm{c}}$ & $75,94 \pm 1,10^{\mathrm{b}}$ & $80,67 \pm 0,62^{\mathrm{a}}$ \\
Encolhimento (\%) & $20,83 \pm 1,52^{\mathrm{a}}$ & $19,42 \pm 2,50^{\mathrm{a}}$ & $22,85 \pm 7,93^{\mathrm{a}}$ & $15,70 \pm 2,72^{\mathrm{a}}$ \\
PPMO (\%) & $30,63 \pm 5,77^{\mathrm{a}}$ & $29,85 \pm 1,60^{\mathrm{ab}}$ & $25,76 \pm 4,48^{\mathrm{ab}}$ & $22,64 \pm 0,96^{\mathrm{b}}$ \\
\hline
\end{tabular}

C1: sem redução de gordura e sal e sem adição de fibra de aveia; C2: com redução de gordura e sal e sem adição de fibra de aveia; T1: com redução de gordura e sal e com adição de 3\% de fibra de aveia; T2: com redução de gordura e sal e com adição de $6 \%$ de fibra de aveia. abc Letras diferentes na mesma linha indicam médias estatisticamente diferentes pelo teste de Tukey $(p \leq 0,05)$. PPMO: perda de peso no micro-ondas. 
Efeito da adição de fibra de aveia sobre as propriedades físico-químicas de hambúrguer cozido e congelado com redução de gordura e sal

Trevisan, Y. C. et al.

resultado da umidade às quantidades de água adicionadas na formulação de hambúrguer cozido de carne bovina adicionado de farinha do subproduto do abacaxi e óleo de canola, como substitutos de gordura. Não houve diferença entre as formulações T2 e T1, e T1 não diferiu de C2 para teor de umidade. A formulação T2 foi diferente de $\mathrm{C} 2$, mostrando que a adição de $6 \%$ de fibra de aveia contribuiu para diminuir a umidade dos hambúrgueres com redução de gordura e sal, provavelmente devido à menor quantidade de água adicionada. Com relação ao teor de cinzas, a formulação C1 apresentou o maior valor, mostrando que a gordura colaborou para esse resultado, enquanto o menor teor foi verificado em T2 e não houve diferença significativa entre as formulações C2 e T1.

Quando comparada com a formulação C1, C2 apresentou redução de $19 \%$ de gordura e T1 e T2 apresentaram redução de 35\% (Tabela 2). Apesar de a quantidade da gordura suína adicionada ter sido de 3,7\% (Tabela 1), há outras fontes de gordura presentes nas matérias-primas (acém bovino e carne mecanicamente separada de frango), explicando a diferença encontrada. Para teor proteico, somente a formulação T2 apresentou valor significativamente menor ao das demais. Como todos os tratamentos tiveram a adição da mesma quantidade de carne, essa variação pode ser devido à variação de proteína da matéria-prima cárnea.

Observou-se que a formulação T2 apresentou o maior rendimento, indicando que a adição de $6 \%$ de fibra de aveia ajudou a aumentar o rendimento de hambúrguer cozido de carne bovina e carne mecanicamente separada de frango com redução de gordura e de sal. Oliveira et al. (2013) observaram valores maiores de rendimento para o tratamento com maior adição da farinha de linhaça dourada ao utilizar este ingrediente como substituto de gordura em hambúrguer de carne bovina com teor reduzido de sódio. A utilização de 3\% e 6\% de fibra de aveia aumentou o rendimento de hambúrguer de carne bovina com reduzido teor de gordura, quando comparado com as formulações com $20 \%$ e $10 \%$ de adição de gordura (BIS, 2016). A formulação T1 apresentou um rendimento similar ao da $\mathrm{C} 1$, indicando que a adição de $3 \%$ de fibra de aveia ajudou a manter o rendimento, mesmo com uma redução de gordura e sal.

Dentre as vantagens da utilização de fibra de aveia em produtos cárneos como substituto de gordura, destaca-se sua alta capacidade de retenção de água que auxilia no aumento do rendimento do produto final (TALUKDER, 2015). O aumento na porcentagem de fibra de aveia solúvel ( $\beta$-Glucana), adicionada em um produto cárneo cozido com redução de gordura, aumentou significativamente o rendimento (PIÑERO et al., 2008; ÁLVAREZ; BARBUT, 2013).

Em relação ao encolhimento dos hambúrgueres, não foi observada diferença significativa entre as formulações estudadas, sugerindo que as alterações realizadas na formulação não afetaram o diâmetro dos hambúrgueres. Resultado similar foi obtido por Piñero et al. (2008), que, ao substituir a gordura suína por fibra de aveia em hambúrgueres bovinos, não obteve diferença no encolhimento dos produtos, apesar de a amostra controle ter apresentado um rendimento menor. Os autores atribuíram este fato à capacidade da fibra de aveia em resistir às mudanças no formato do produto final. Em estudo com hambúrguer de carne bovina, Bis (2016) relata que o maior encolhimento foi observado para o tratamento com redução de gordura e sem adição de fibra de aveia, enquanto o tratamento com menor encolhimento foi com adição de $6 \%$ de fibra de aveia.

Já na análise de PPMO, a formulação T2 apresentou a menor perda de peso, mostrando que a adição de $6 \%$ de fibra de aveia colaborou com esta propriedade no reaquecimento. A Figura 1 mostra os hambúrgueres após aquecimento por micro-ondas.

Os resultados obtidos na determinação do $\mathrm{pH}$ durante estocagem estão apresentados na Tabela 3. Na medição realizada logo após o processamento das amostras, observou-se que apenas T2 (com adição de $6 \%$ de fibra de aveia) apresentou valores estatisticamente diferentes dos demais tratamentos, indicando que a adição de $6 \%$ de fibra de aveia ( $\mathrm{pH}$ entre 5,5 e 7,5) reduziu o $\mathrm{pH}$ do hambúrguer após o cozimento em 0 dia e 60 dias de estocagem (Tabela 3). Esses resultados foram similares aos obtidos por Selani et al. (2016) que, em hambúrgueres

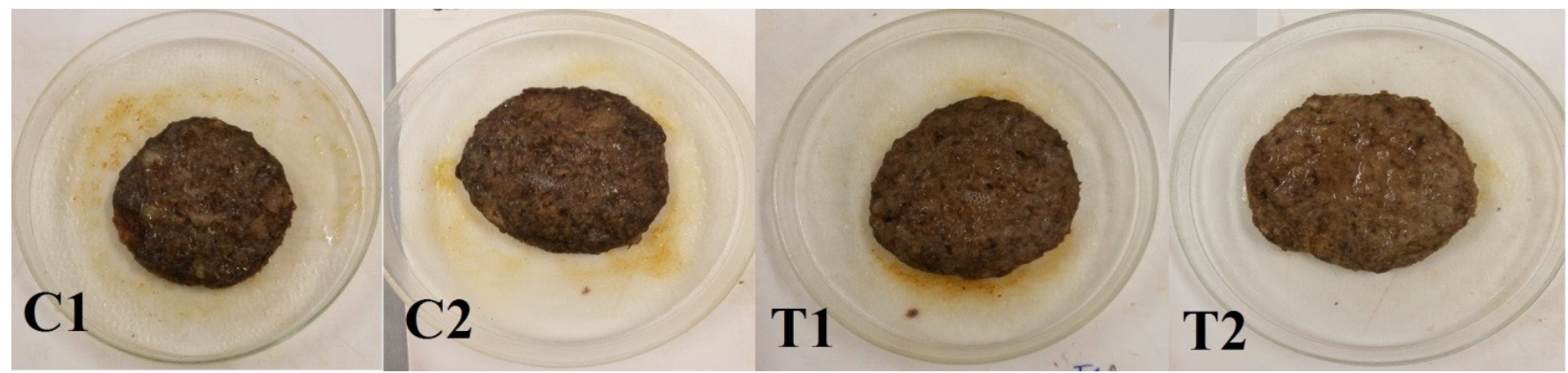

Figura 1. Hambúrgueres após aquecimento por micro-ondas. 
Efeito da adição de fibra de aveia sobre as propriedades físico-químicas de hambúrguer cozido e congelado com redução de gordura e sal

Trevisan, Y. C. et al.

cozidos adicionados de 1,5\% de resíduos de processamento de abacaxi, os valores de $\mathrm{pH}$ foram menores que os do controle e, após 30 dias de estocagem sob congelamento, os tratamentos não apresentaram diferença significativa entre si. $\mathrm{O}$ pH da fibra de aveia possivelmente colaborou com esse resultado.

A Figura 2 apresenta os resultados de cor instrumental durante a estocagem. A coloração de produtos cárneos cozidos é afetada também pela estocagem sob congelamento (BERRY; BIGNER-GEORGE, 2000). Depois do processamento (0 dia de estocagem), os menores valores de $L^{*}$ encontrados foram para as formulações C2 e T1, e foram diferentes de C1 e T2. O valor $L^{*}$ para T2 se manteve durante estocagem em 0, 30 e 60 dias sob congelamento, mostrando que a adição de $6 \%$ de fibra de aveia colaborou com a manutenção do valor L* durante estocagem. Rehab et al. (2011) substituíram parcialmente a gordura suína por amido de batata reidratado em hambúrgueres cozidos de carne bovina e observaram que o valor de $L^{*}$ foi significativamente maior para o tratamento com a maior adição do substituto, além de ser diferente do controle, após um período de estocagem sob congelamento.

A formulação C1 apresentou o menor valor de $a^{*}$, intensidade da cor vermelha, seguido de T2. Como C1

Tabela 3. Valores de $\mathrm{pH}$ nos dias 0, 30 e 60 após o processamento $(n=3)$, durante a estocagem sob congelamento.

\begin{tabular}{lc|c|c}
\multirow{2}{*}{ Formulação } & \multicolumn{3}{c}{$\mathbf{p H}$} \\
\cline { 2 - 4 } & $\mathbf{0 ~ d i a}$ & $\mathbf{3 0}$ dias & $\mathbf{6 0}$ dias \\
C1 & $6,30 \pm 0,03^{\mathrm{a}}$ & $6,20 \pm 0,03^{\mathrm{a}}$ & $6,28 \pm 0,01^{\mathrm{a}}$ \\
C2 & $6,32 \pm 0,02^{\mathrm{a}}$ & $6,22 \pm 0,02^{\mathrm{a}}$ & $6,25 \pm 0,01^{\mathrm{ab}}$ \\
T1 & $6,28 \pm 0,02^{\mathrm{a}}$ & $6,22 \pm 0,01^{\mathrm{a}}$ & $6,27 \pm 0,01^{\mathrm{ab}}$ \\
T2 & $6,02 \pm 0,09^{\mathrm{b}}$ & $6,20 \pm 0,00^{\mathrm{a}}$ & $6,24 \pm 0,01^{\mathrm{b}}$ \\
\hline
\end{tabular}

C1: sem redução de gordura e sal e sem adição de fibra de aveia; C2: com redução de gordura e sal e sem adição de fibra de aveia; T1: com redução de gordura e sal e com adição de 3\% de fibra de aveia; T2: com redução de gordura e sal e com adição de $6 \%$ de fibra de aveia. ab Letras diferentes na mesma coluna indicam médias estatisticamente diferentes pelo teste de Tukey $(p \leq 0,05)$. contém a maior concentração de gordura e T2 a maior concentração de fibra de aveia, tanto a gordura como a fibra de aveia diminuíram o valor a* em 0, 30 e 60 dias de estocagem. Já o tratamento com adição de 3\% de fibra de aveia apresentou o maior valor $a^{*}$ durante a estocagem. A redução da gordura diminuiu o valor $L^{*}$ e aumentou o valor $a^{*}$. Já em estudo realizado por Selani et al. (2016), em que a gordura suína foi parcialmente substituída em hambúrguer cozido de carne bovina por resíduos de processamento do abacaxi e óleo de canola, observou-se que o valor $a^{\star}$ dos dois tratamentos com adição dos substitutos foram menores que o controle com baixo teor de gordura (10\% de gordura) e similar ao controle convencional (com 20\% de gordura). Somente a formulação com adição de óleo de canola apresentou resultados iguais aos controles. Neste caso, os resíduos do processamento de abacaxi influenciaram a diminuição do valor de $a^{*}$, diferente do que ocorreu em nosso estudo, em que a fibra de aveia na concentração de 3\% auxiliou no aumento do valor $a^{*}$.

Os maiores valores para $b^{*}$ foram verificados nas formulações T1 e T2, os quais se mostraram mais estáveis durante estocagem. A adição de fibra de aveia contribuiu para o aumento do valor $b^{*}$ em hambúrgueres cozidos, nas concentrações utilizadas. Resultado similar foi relatado por Rehab et al. (2011), os quais afirmaram que os tratamentos de hambúrguer de carne bovina com redução de gordura apresentaram valores $b^{*}$ maiores do que o controle.

A Tabela 4 mostra os resultados do perfil de textura dos hambúrgueres cozidos congelados. De acordo com Huang et al. (2011), a dureza representa um dos parâmetros mais importantes da textura de produtos cárneos, influenciando a preferência do consumidor. Houve redução $(p \leq 0,05)$ da dureza quando o teor de gordura foi diminuído, ou seja, quando se compararam as formulações C1 com C2. Quando a fibra de aveia foi adicionada houve um aumento $(p \leq 0,05)$ da dureza dos hambúrgueres e estas formulações ficaram semelhantes à C1. As formulações
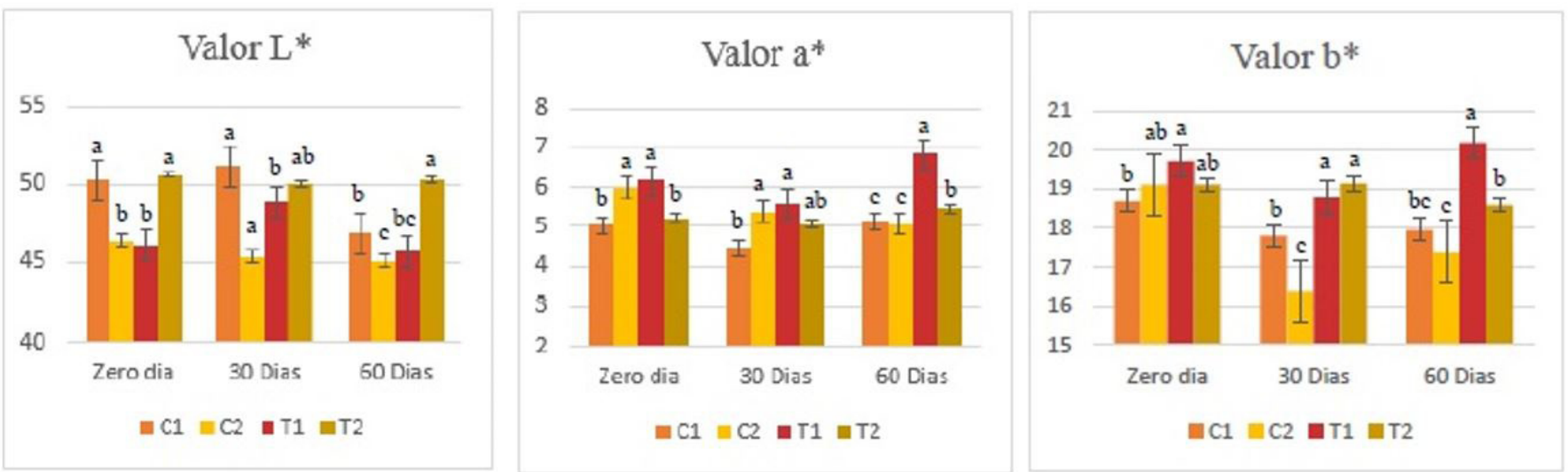

Figura 2. Valor $L^{*}, a^{*}$ e $b^{\star}$ para os hambúrgueres cozidos durante estocagem sob congelamento. C1: sem redução de gordura e sal e sem adição de fibra de aveia; C2: com redução de gordura e sal e sem adição de fibra de aveia; T1: com redução de gordura e sal e com adição de 3\% de fibra de aveia; T2: com redução de gordura e sal e com adição de 6\% de fibra de aveia. 
Efeito da adição de fibra de aveia sobre as propriedades físico-químicas de hambúrguer cozido e congelado com redução de gordura e sal

Trevisan, Y. C. et al.

Tabela 4. Perfil de textura para os hambúrgueres cozidos congelados $(n=3)$.

\begin{tabular}{ccccc} 
Formulação & Dureza (N) & Coesividade & Elasticidade & Mastigabilidade (N/cm) \\
C1 & $46,34 \pm 7,89^{a}$ & $0,0066 \pm 0,0005^{b}$ & $0,7375 \pm 0,0768^{a}$ & $0,22 \pm 0,05^{a}$ \\
C2 & $31,11 \pm 11,03^{\mathrm{b}}$ & $0,0072 \pm 0,0003^{\mathrm{a}}$ & $0,6448 \pm 0,0966^{\mathrm{a}}$ & $0,15 \pm 0,06^{\mathrm{b}}$ \\
T1 & $40,94 \pm 8,25^{\mathrm{ab}}$ & $0,0067 \pm 0,0003^{\mathrm{b}}$ & $0,6816 \pm 0,0636^{\mathrm{a}}$ & $0,19 \pm 0,04^{\mathrm{ab}}$ \\
T2 & $43,51 \pm 7,12^{\mathrm{a}}$ & $0,0065 \pm 0,0002^{\mathrm{b}}$ & $0,6895 \pm 0,0335^{\mathrm{a}}$ & $0,19 \pm 0,03^{\mathrm{ab}}$ \\
\hline
\end{tabular}

C1: sem redução de gordura e sal e sem adição de fibra de aveia; C2: com redução de gordura e sal e sem adição de fibra de aveia; T1: com redução de gordura e sal e com adição de 3\% de fibra de aveia; T2: com redução de gordura e sal e com adição de $6 \%$ de fibra de aveia. ab Letras diferentes na mesma coluna indicam médias estatisticamente diferentes pelo teste de Tukey $(\mathrm{p} \leq 0,05)$.

C1, T1 e T2 apresentaram maior dureza $(p \leq 0,05)$ que C2. A formulação C2 apresentou maior teor de umidade (ver Tabela 2) e isso deve ter contribuído para esse resultado de dureza. Resultado similar foi observado por Yasarlar et al. (2007), que afirmaram que quanto maior a quantidade de farelo de aveia adicionado em almôndegas de carne bovina (5-20\%) maior a dureza, sendo que o tratamento com $20 \%$ de farelo de aveia apresentou o maior valor de dureza. López-Vargas et al. (2014) também relataram aumento da dureza em hambúrguer suíno quando foram adicionados 2,5\% e 5\% de fibra de albedo do maracujá. Em outro estudo, com hambúrguer de carne bovina, foi relatado aumento da dureza quando houve redução de $10 \%$ da gordura adicionada, e nos tratamentos em que houve a adição de 3\% e 6\% de fibra de aveia a dureza apresentou resultado similar ao controle (BIS, 2016).

O mesmo efeito foi observado nos parâmetros mastigabilidade e coesividade, sendo que para as formulações com adição de fibra de aveia, os valores obtidos foram similares aos observados em C1. Quanto à elasticidade, todos os valores encontrados foram similares $(p>0,05)$. Selani et al. (2016) também não verificaram diferença nos resultados de elasticidade, indicando que a substituição da gordura por fibra do subproduto do abacaxi e óleo de canola não afetaram a textura. A redução no teor de sal adicionado na formulação não interferiu nos parâmetros de textura dos hambúrgueres mistos cozidos.

\section{Conclusão}

O uso da fibra de aveia foi considerado efetivo para melhorar as propriedades físico-químicas em hambúrgueres cozidos, como o rendimento, a perda de peso durante aquecimento por micro-ondas e a estabilidade da cor durante estocagem sob congelamento. Não houve alterações da textura, indicando que a fibra de aveia apresenta-se como ingrediente promissor para auxiliar formulações de produtos cárneos com reduzido teor de gordura e sal.

\section{Agradecimentos}

Ao CNPQ (Conselho Nacional de Desenvolvimento Científico e Tecnológico) e à CAPES (Coordenação de Aperfeiçoamento de Pessoal de Nível Superior) pela concessão de bolsas.

\section{Referências}

ÁLVAREZ, D.; BARBUT, S. Effect of inulin, $\beta$-glucan and their mixtures on emulsion stability, color and textural parameters of cooked meat batters. Meat Science, Barking, v. 94, n. 3, p. 320-327, 2013. PMid:23567131. http://dx.doi.org/10.1016/j. meatsci.2013.02.011

BARRETTO, A. C. S.; PACHECO, M. T. B.; POLLONIO, M. A. R. Effect of the addition of wheat fiber and partial pork back fat on the chemical composition, texture and sensory property of low-fat bologna sausage containing inulin and oat fiber. Food Science and Technology, Campinas, v. 35, n. 1, p. 100-107, 2015. Disponível em: <http://www.scielo.br/scielo. php?pid=S010120612015000100100\&script=sci_arttext>. Acesso em: 05 ago. 2015.

BERRY, B. W.; BIGNER-GEORGE, M. E. Factors affecting color properties of beef patties on an outdoor gas grill. Journal of Muscle Foods, Malden, v. 11, n. 3, p. 213-226, 2000. http:// dx.doi.org/10.1111/j.1745-4573.2000.tb00426.x.

BIS, C. V. Efeito das fibras alimentares como substitutos de gordura em hambúrguer de carne bovina e paio. 2016. 116 f. Dissertação (Mestrado em Engenharia e Ciência de Alimentos)-Instituto de Biociências, Letras e Ciências Exatas, Universidade Estadual Paulista "Júlio de Mesquita Filho", São José do Rio Preto, 2016. Disponível em: <http://repositorio.unesp. br/handle/11449/135877>. Acesso em: 27 abr. 2016.

BLIGH, E. G.; DYER, W. J. A rapid method of total lipid extraction and purification. Canadian Journal of Biochemistry and Physiology, Ottawa, v. 37, n. 8, p. 911-917, 1959. PMid:13671378. http://dx.doi.org/10.1139/059-099.

BORTNOWSKA, G.; BALEJKO, J.; SCHUBE, V.; TOKARCZYK, G.; KRZEMIŃSKA, N.; MOJKA, K. Stability and physicochemical properties of model salad dressings prepared with pre gelatinized potato starch. Carbohydrate Polymers, Oxford, v. 111, p. 624-632, 2014. PMid:25037397. http://dx.doi.org/10.1016/j. carbpol.2014.05.015.

BRASIL. Ministério da Agricultura, Pecuária e Abastecimento. Instrução normativa n ${ }^{\circ} 20$ de 31 de julho de 2000. Regulamento técnico de identidade e qualidade de hambúrguer. Diário Oficial [da] República Federativa do Brasil, Brasília, DF, 31 jul. 2000. Disponível em: <http://extranet.agricultura.gov.br/ sislegis-consulta/consultarLegislacao.do?operacao=visualiza r\&id=1681 >. Acesso em: 05 abr. 2015. 
Efeito da adição de fibra de aveia sobre as propriedades físico-químicas de hambúrguer cozido e congelado com redução de gordura e sal

Trevisan, Y. C. et al.

CHOE, J. H.; KIM, H. Y.; LEE, J. M.; KIM, Y. J.; KIM, C. J. Quality of frankfurter-type sausages with added pig skin and wheat fiber mixture as fat replacer. Meat Science, Barking, v. 93, n. 4, p. 849-854, 2013. PMid:23313971. http://dx.doi.org/10.1016/j. meatsci.2012.11.054

CHOI, Y. S.; PARK, K. S.; KIM, H. W.; HWANG, K. E.; SONG, D. H.; CHOI, M. S.; LEE, S. Y.; PAIK, H. D.; KIM, C. J. Quality characteristics of reduced-fat frankfurters with pork fat replaced by sunflower seed oils and dietary fiber extracted from makgeolli lees. Meat Science, Barking, v. 93, n. 3, p. 652-658, 2013. PMid:23273477. http://dx.doi.org/10.1016/j.meatsci.2012.11.025.

CIVILLE, C. V.; SZCZESNIAK, A. S. Guidelines to training a texture profile panel. Journal of Texture Studies, Westport, v. 4, n. 2, p. 204-223, 1973. http://dx.doi.org/10.1111/j.1745-4603.1973. tb00665.x.

COFRADES, S.; ANTONIOU, I.; SOLAS, M. T.; HERRERO, A. M.; JIMÉNEZ-COLMENERO, F. Preparation and impact of multiple (water-in-oil-in-water) emulsions in meat systems. Food Chemistry, London, v. 141, n. 1, p. 338-346, 2013. PMid:23768366. http:// dx.doi.org/10.1016/j.foodchem.2013.02.097.

COFRADES, S.; SANTOS-LÓPEZ, J. A.; FREIRE, M.; BENEDÍ, J.; SÁNCHEZ-MUNIZ, F. J.; JIMÉNEZ-COLMENERO, F. Oxidative stability of meat systems made with W1/O/W2 emulsions prepared with hydroxytyrosol and chia oil as lipid phase. LWT - Food Science and Technology, Amsterdam, v. 59, n. 2, p. 941-947, 2014. http://dx.doi.org/10.1016/j.Iwt.2014.06.051.

FERNÁNDEZ-GINÉS, J. M.; FERNÁNDEZ-LÓPEZ, J.; SAYASBARBERÁ, E.; PÉREZ-ALVAREZ, J. A. Meat products as functional foods. Journal of Food Science, Chicago, v. 70, n. 2, p. 37-43, 2005. http://dx.doi.org/10.1111/j.1365-2621.2005.tb07110.x.

HORITA, C. N.; MORGANO, M. A.; CELEGHINI, R. M. S.; POLLONIO, M. A. R. Physico-chemical and sensory properties of reduced-fat mortadella prepared with blends of calcium, magnesium and potassium chloride as partial substitutes for sodium chloride. Meat Science, Barking, v. 89, n. 4, p. 426-433, 2011. PMid:21645975. http://dx.doi.org/10.1016/j.meatsci.2011.05.010

HORWITZ, W. (Ed.). Official methods of analysis of the Association of Official Analytical Chemists. 18th ed. Washington, D.C.: AOAC, 2007.

HUANG, S. C.; TSAI, Y. F.; CHEN, C. M. Effects of wheat fiber, oat fiber, and inulin on sensory and physic-chemical properties of Chinese-style sausages. Asian-Australasian Journal of Animal Sciences, Seoul, v. 24, n. 6, p. 875-880, 2011. http:// dx.doi.org/10.5713/ajas.2011.10317.

KEETON, J. T. Low-fat meat products-technological problems with processing. Meat Science, Barking, v. 36, n. 1-2, p. 621-276, 1994. PMid:22061464. http://dx. doi.org/10.1016/0309-1740(94)90045-0.

KTARI, N.; SMAOUI, S.; TRABELSI, I.; NASRI, M.; BEN SALAH, R. Chemical composition, techno-functional and sensory properties and effects of three dietary fibers on the quality characteristics of Tunisian beef sausage. Meat Science, Barking, v. 96, n. 1, p. 512-525, 2014. PMid:24013695. http://dx.doi.org/10.1016/j. meatsci.2013.07.038

LÓPEZ-VARGAS, J. H.; FERNÁNDEZ-LÓPEZ, J.; PÉREZ-ÁLVAREZ, J. A.; VIUDA-MARTOS, M. Quality characteristics of pork Burger added with albedo-fiber powder obtained from yellow passion fruit (Passiflora edulis var. flavicarpa) co-products. Meat Science, Barking, v. 97, n. 2, p. 270-276, 2014. PMid:24607997. http:// dx.doi.org/10.1016/j.meatsci.2014.02.010.

MANSOUR, E. H.; KHALIL, A. H. Characteristics of low-fat beef burgers as influenced by various types of wheat fibers. Food Research International, London, v. 30, n. 4, p. 199-205, 1999. Disponível em: <http://onlinelibrary.wiley.com/doi/10.1002/ (SICI)1097-0010(19990315)79:4\%3C493::AID-JSFA4\%3E3.0.CO;2-5/ abstract>. Acesso em: 11 set. 2015.

OLIVEIRA, D. F.; COELHO, A. R.; BURGARDT, V. C. F.; HASHIMOTO, E. H.; LUNKES, A. M.; MARCHI, J. F.; TONIAL, I. B. Alternativas para um produto cárneo mais saudável: uma revisão. Brazilian Journal of Food Technology, Campinas, v. 16, n. 3, p. 163-174, 2013. http://dx.doi.org/10.1590/S1981-67232013005000021.

PIÑERO, M. P.; PARRA, K.; HUERTA-LEIDENZ, N.; ARENAS DE MORENO, L.; FERRER, M.; ARAUJO, S.; BARBOZA, Y. Effect of oat's soluble fibre (beta-glucan) as a fat replacer on physical, chemical, microbiological and sensory properties of low-fat beef patties. Meat Science, Barking, v. 80, n. 3, p. 675-680, 2008. PMid:22063581. http://dx.doi.org/10.1016/j.meatsci.2008.03.006.

REHAB, F. M. A.; EL-ANANY, A. M.; GAAFAR, A. M. Effect of potato flakes as fat replacer on the quality attributes of low-fat beef patties. Advance Journal of Food Science and Technology, Faisalabad, v. 3, n. 3, p. 173-180, 2011. Disponível em: <http:// maxwellsci.com/jp/abstract. php?jid=AJFST\&no=118\&abs=03>. Acesso em: 02 dez. 2015.

RUUSUNEN, M.; PUOLANNE, E. Reducing sodium intake from meat products. Meat Science, Barking, v. 70, n. 3, p. 531-541, 2005. PMid:22063751. http://dx.doi.org/10.1016/j.meatsci.2004.07.016.

SALCEDO-SANDOVAL, L.; COFRADES, S.; PÉREZ, C. R.-C.; SOLAS, M. T.; JIMÉNEZ-COLMENERO. Healthier oils stabilized in konjac matrix as fat replacers in n-3 PUFA enriched frankfurters. Meat Science, Barking, v. 93, n. 3, p. 757-786, 2013. PMid:23261536. http://dx.doi.org/10.1016/j.meatsci.2012.11.038.

SANTOS, B. A.; CAMPAGNOL, P. C. B.; MORGANO, M. A.; POLLONIO, M. A. R. Monosodium glutamate, disodium inosinate, disodium guanylate, lysine and taurine improve the sensory quality of fermented cooked sausages with $50 \%$ and $75 \%$ replacement of $\mathrm{NaCl}$ with $\mathrm{KCl}$. Meat Science, Barking, v. 96, n. 1, p. 509-513, 2014. PMid:24008059. http://dx.doi.org/10.1016/j. meatsci.2013.08.024

SCHMIELE, M.; MASCARENHAS, M. C. C. N.; BARRETTO, A. C. S.; POLLONIO, M. A. R. Dietary fiber as fat substitute in emulsified and cooked meat model system. LWT - Food Science and 
Efeito da adição de fibra de aveia sobre as propriedades físico-químicas de hambúrguer cozido e congelado com redução de gordura e sal

Trevisan, Y. C. et al.

Technology, Amsterdam, v. 61, n. 1, p. 105-111, 2015. http:// dx.doi.org/10.1016/j.Iwt.2014.11.037.

SELANI, M. M.; SHIRADO, A. N.; MARGIOTTA, G. B.; SALDAÑA, E.; SPADA, F. P.; PIEDADE, S. M. S.; CONTRERAS-CASTILLO, C. J.; CANNIATTI-BRAZACA, S. G. Effects of pineapple by product and canola oil as fat replacers on physicochemical and sensory qualities of low-fat beef burger. Meat Science, Barking, v. 112, n. 1, p. 69-76, 2016. PMid:26562792. http://dx.doi.org/10.1016/j. meatsci.2015.10.020.

TALUKDER, S. Effect of dietary fiber on properties and acceptance of meat products: a review. Critical Reviews in Food Science and Nutrition, Cleveland, v. 55, n. 7, p. 1005-1011, 2015. PMid:24915339. http://dx.doi.org/10.1080/10408398.2012.682230.

TOMASCHUNAS, M.; ZÖRB, R.; FISCHER, J.; KÖHN, E.; HINRICHS, J.; BUSCH-STOCKFISCH, M. Changes in sensory properties and consumer acceptance of reduced fat pork Lyon-style and liver sausages containing inulin and citrus fiber as fat replacers. Meat
Science, Barking, v. 95, n. 3, p. 629-640, 2013. PMid:23811098. http://dx.doi.org/10.1016/j.meatsci.2013.06.002.

ULU, H. Effect of wheat flour, whey protein concentrate and soya protein isolate on oxidative processes and texture properties of cooked meatballs. Food Chemistry, London, v. 87, n. 4, p. 523-529, 2004. http://dx.doi.org/10.1016/j.foodchem.2004.01.002. WEISS, J.; GIBIS, M.; SCHUH, V.; SALMINEN, H. Advances in ingredient and processing systems for meat and meat products. Meat Science, Barking, v. 86, n. 1, p. 196-213, 2010. PMid:20619800. http://dx.doi.org/10.1016/j.meatsci.2010.05.008.

YASARLAR, E. E.; DAGLIOGLU, O.; YILMAZ, I. Effect of cereal bran addition on chemical composition, cooking characteristics and sensory properties of Turkish meatballs. Asian Journal of Chemistry, Ghaziabad, v. 19, n. 3, p. 2353-2361, 2007.

YILMAZ, I.; DAGHOGLU, O. The effect of replacing fat with oat bran on fatty acid composition and physicochemical properties of meatballs. Meat Science, Barking, v. 65, n. 2, p. 819-823, 2003. PMid:22063444. http://dx.doi.org/10.1016/S0309-1740(02)00286-3. 